\title{
Aesthetics Application in Solid Waste Management as a Means of Optimising Environmental Sustainability in Urbanizing Third-World Environments
}

\author{
Odji Ebenezer ${ }^{\mathrm{a}}$ \\ ${ }^{a}$ Federal University of Technology, Akure, 340252, Ondo State, Nigeria
}

Received: 06 March 2019; Accepted: 07 June 2019; Published: 08 July 2019

\begin{abstract}
The increasing urbanization of many third-world cities has led to increased generation of solid wastes which are often ill-managed and indiscriminately dumped, posing grave challenges to local environmental engineers and designers. This has consequently reduced the sustainability of many built and natural African environments. Therefore, this study was aimed at practically applying aesthetics in solid waste management as a means of optimizing sustainability in urbanizing West African environments. Adopting a descriptive approach supported with direct observation, with a total sample size of 610 , respondents were purposively sampled in selected research sites in Nigeria. Following one hypothesis testing, the study showed a significant association between improved environmental affordance (derived from aesthetics) and the alleviation of negative user responses to the environment (such as indiscriminate dumping of solid wastes). The study also showed that more aesthetically negative environments offers more negative environmental affordance than positive environmental affordance. The results confirm that the majority of users of the environments (humans) exhibit more positive environmental behaviours when positive affordance is perceived from the environment. The study therefore established the significance of the practical application of aesthetics in the management of solid wastes in urbanizing third world environments.
\end{abstract}

Index Terms: Aesthetics, Design-Theory, Environment, Sustainability, Urbanization, Affordance.

(C) 2019 Published by MECS Publisher. Selection and/or peer review under responsibility of the Research Association of Mode rn Education and Computer Science

\footnotetext{
* Corresponding author.

E-mail address: ezerodjimin@gmail.com
} 


\section{Introduction}

Sub-Saharan Africa is often referred to as the least urbanized region in the world [1, 2]. However, Sub-Saharan Africa is urbanizing quickly, with cities and or towns growing at an annual rate of around $4 \%$ over the last two decades and more [3]. However, this noticeable urbanization rate increase comes with some major environmental sustainability retardation trends and conditions especially in relatively less planned and minimally organized Sub-Saharan states like Nigeria, Ghana, Republic of Cote d'Ivoire, Cameroun and Niger, especially in the western African region. Generally, more than half of the world's population reside and work in urban areas $[4,5]$.

\section{Nomenclature}

A.P. $\quad$ Aesthetic Positivity: Degree of resulting attractiveness/beauty and sensibility

A.N. Aesthetic Negativity: Degree of resulting unattractiveness/ugliness/untidiness

E.A.S.T. The Environmental Aesthetics and Sustainability Theory

E.A. Environmental Affordance

P.E.A. Positive Environmental Affordances

N.E.A. Negative Environmental Affordances

This estimation is predicted to increase to about two-third of the population by 2050 [6] and Nigeria is not an exception. It has been confirmed that half of Nigeria's population is in urban residences [7]. This urbanization trend poses various challenges including:

- $\quad$ shortage of basic social amenities [7]

- $\quad$ excessive pressure on existing amenities and essential services $[5,8]$

- $\quad$ excessive pressure on the environment

- $\quad$ higher risk of contracting and spreading diseases such as malaria [4] and other public health disasters [e.g. 9]

- lack of habitable houses for humans [7]

- $\quad$ increased crime rate

- $\quad$ land and water pollution [9]

- $\quad$ obstruction of drainages [9] (Figure 1)

- $\quad$ slum creation [8]

- $\quad$ traffic [8], human and other forms of congestion (Figure 2)

- difficulties in managing natural or man-made disasters

- $\quad$ aesthetic negativity [10]

- increased generation and indiscriminate dumping of solid wastes 


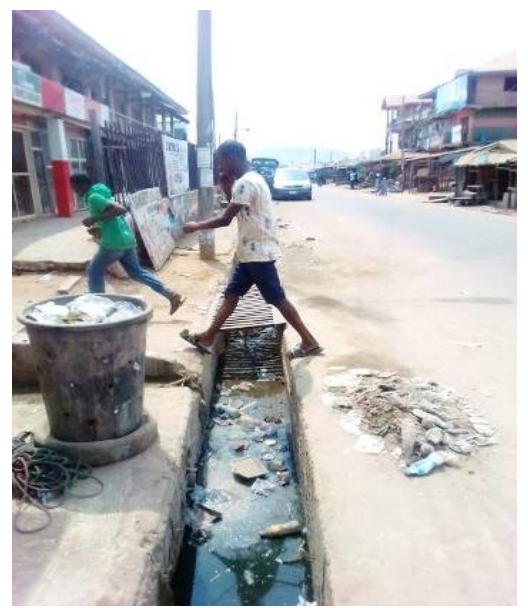

Fig. 1. Showing drainage littering and blockage

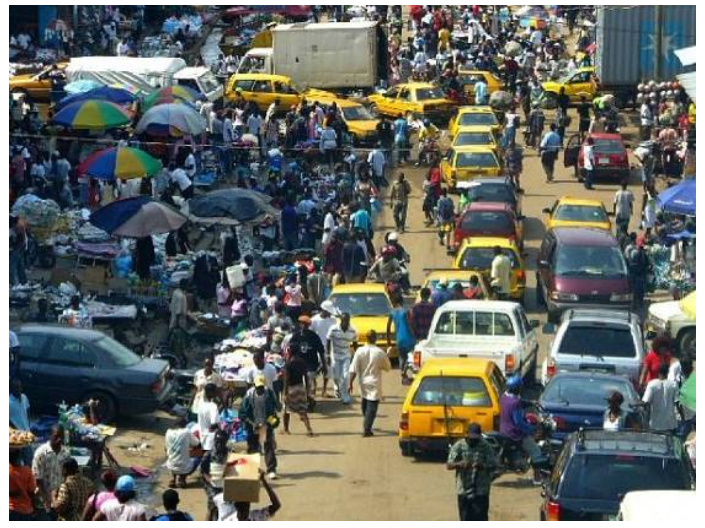

Fig. 2. Showing traffic, human and other forms of congestion [6]

These aforementioned challenges, and such like, pose major threats to environmental sustainable and development in Nigeria and in Sub-Saharan African at large. Perhaps, the most significant to this current study is the aesthetic negativity accruing from the dense population as a result of increased urbanization. This is not very unrelated to created slum problems. Most western African urban environments share various common characteristics and practices. One of such characteristics is aesthetic destitution herein referred to as aesthetic negativity (AN). AN is the quality or degree of unattractiveness, ugliness, untidiness, disorganization, etc. that a design or environment possesses as perceived by the user or observer.

One major contributor to AN in Nigeria is indiscriminate dumping of generated solid wastes, both biodegradable and non-biodegradable wastes which is a common sight in many states in developing western Africa (Figures 1, 3 and 4) defacing both the built and the natural environment. Garbage ridden streets and waterways are common sites in West Africa (figures 4 and 5) that local environmental engineers, designers, conservers and other authorities have to contend with. Greater populations generate greater wastes. There are a lot of paper works, roundtable talks, decisions and few practical attempts being made in this region, but the results are obviously noticeable in the aesthetic negativity of the environments of the region (figures $1,3,4$ and 5). 


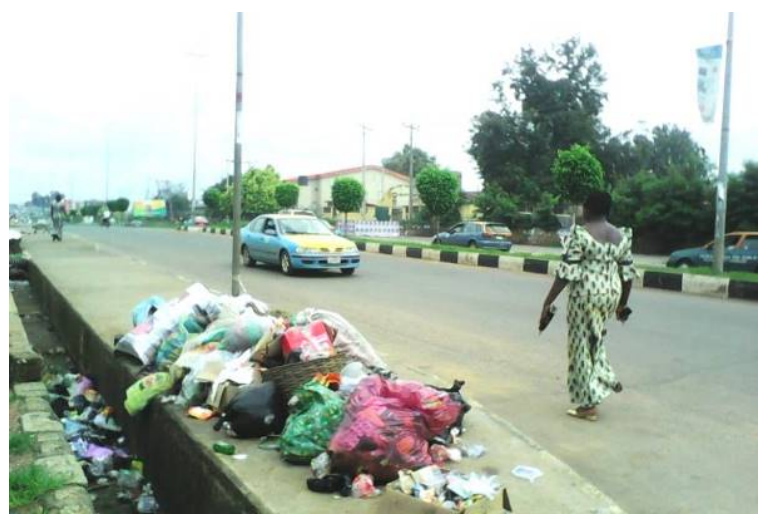

Fig. 3. Showing indiscriminate dumping of generated solid wastes in Nigeria

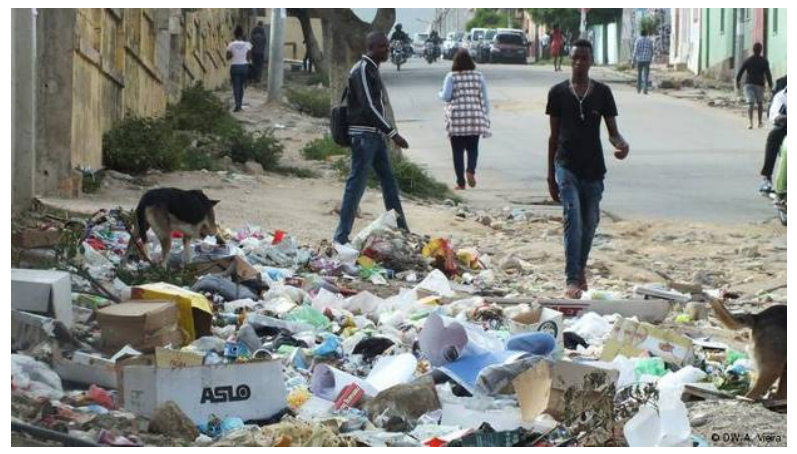

Fig. 4. Showing indiscriminate dumping of generated solid wastes on the street in Ghana [11]

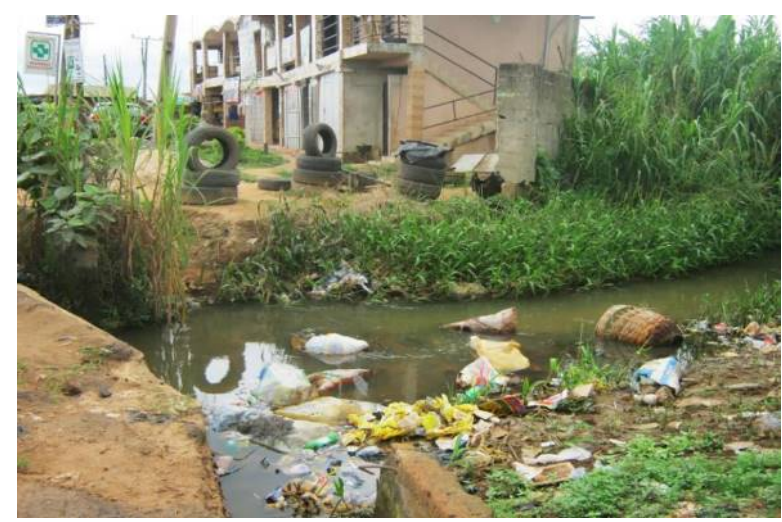

Fig. 5. Showing indiscriminate dumping of solid wastes in watercourses in Nigeria

The increasing urbanization trend in developing countries is simultaneously resulting in the generation of greater solid wastes and, like it is in Nigeria which is representative of most western African states as at the time of this study, these generated solid wastes are often indiscriminately dumped by both those who generate them as well as, sometimes, those who are supposed to manage them, grossly mismanaged or basically 
managed at best as most west African waste processing sites can only yet boast of. This diminishes environmental aesthetics and sustainability. Hence, there is the need to curb this negative trend if environmental sustainability is to be improved. But, how may this be achieved?

Firstly, if the generated wastes are not indiscriminately disposed, then the environment will suffer less AN. However, how may this be achieved without undue force or brutality, i.e. on the part of the environmental law enforcers against defaulters, as is common in most African countries? The answer lies in the appeal to the will, sense of judgement and or perception of the user of the environment, not necessarily directly by the law enforcers, environmentalists or conservers, but by the environment itself. Environmental engineers, designers and conservers may successfully manage solid wastes indirectly by consciously designing appropriate affordances into the environment.

This paper is of the position that the environment user's attitude towards the environment is usually more of a response to the influence the environment itself is having on the human-user than otherwise. This paper, therefore, proposes that if the attitude and perception of the humans towards the environment is favourably adjusted, it will serve to alleviate anti-environmental-sustainability behaviour. This will in turn improve the environmental AP, simultaneously alleviating AN, and hence improving the sustainability of any environment. However, the success of this depends largely on the impression the environment itself creates in the mind of the user or observer before or as he/she uses the environment.

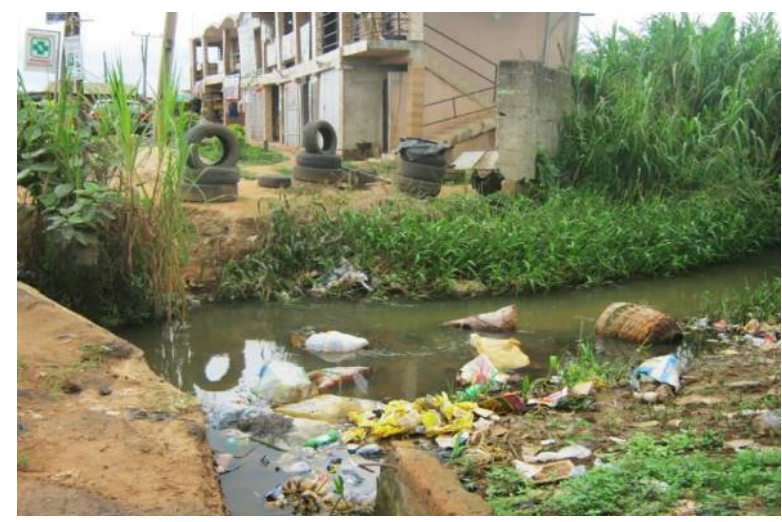

Fig. 5. Showing indiscriminate dumping of solid wastes in watercourses in Nigeria

\section{Aesthetics, Environmental Affordance and User Response}

An earlier study [12] interchangeably used the terms affective and aesthetic responses indicating a close-cut relationship between the environment-user's affective response and the aesthetic response to the environment. These factors are central to behaviour or conscious experience in both the built and the natural environment [12]. Apparently, aesthetics is one of the most important benefits realized by many users in the environment $[13,14,15]$. In practise, some users consciously desire and or demand for aesthetic sensibility in environmental designs [15].

A fairly recent study [16] viewed aesthetics as an evaluative process that stimulates the anticipation for stable and successful interactions of the user with the environment suggesting that aesthetics provides for "sense-making" as it influences what the user may anticipate by an action tendency with respect to the environment. In other words, environmental aesthetics influences the perception and, over time, attitude of the user of the environment. Another fairly recent study [17] linked the attitude of the user and the practice of solid waste management. This means that proper solid waste management is a function of the attitude of the 
user of the environment towards the environment. However, contrary to this view, the user's attitude is a function of the perception of the user which is framed partly by the aesthetics value and affordance of the environment this study posits.

Therefore, this research proposes that the practice of waste management can be influenced by environmental designers (engineers, architects, environmental scientists, industrial designers, surveyors, builders and the artist, etc.) who are tasked with the responsibility of creating, shaping, innovating or conserving the environment, be it built or natural using AN or AP as a means of generating environmental affordances (EA) which consequently shapes the attitudinal or behavioural responses of the user of the environment. Environmental affordance are the properties of the environment that suggests the possible actions users may take while using it, thereby suggesting how users may interact with that specific environment. For example, an environment with strong AN (e.g. figures 4, 5 and 6) may suggest to the user that "it is okay to dump your trash here" without the user feeling any form of uneasiness, guilt or restrain even though these indiscriminate dumping sites are located at the centre of the cities. Whereas scenes like the one shown in figure 7 may suggest otherwise. EA impresses on the user's mind how he or she may interact with the environment.

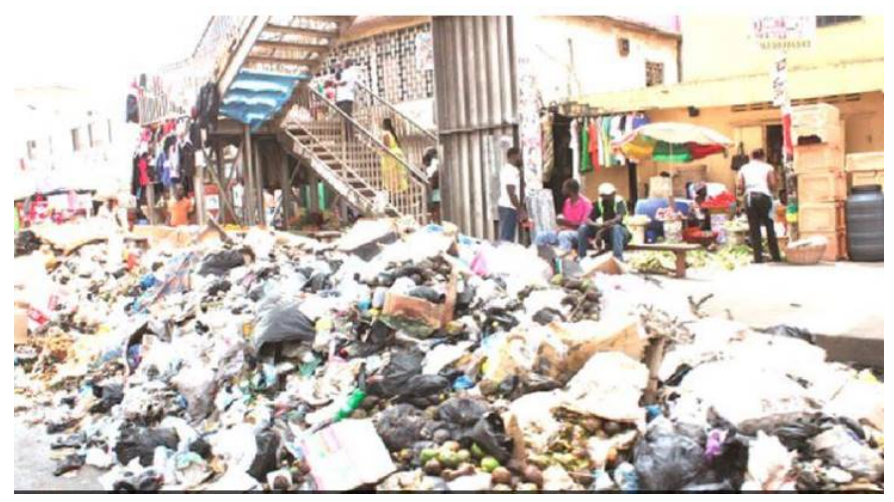

Fig. 6. Showing an environment with high AN in Ghana [18]

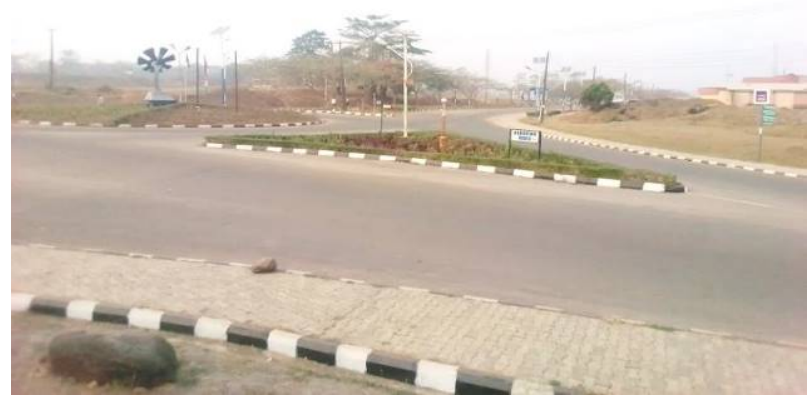

Fig. 7. Showing an environment with high AP in Nigeria 
However, to avoid undue assumptions, this study investigated how the aesthetic value of an environmental scene (AN or AP) may influence environment users' response to the environment in relation to environmental affordance. Although, there have been few researches conducted as relating to environmental affordance, for example an environmental study [19] established interconnections between environmental affordances and green space design attributes which addressed users' concerns and expectations. However, most of the previous studies only attempted to answer the question of 'why' with little or no practical application especially as relating to third world environments. Therefore, this study was aimed at providing practical application of aesthetics and affordances for the sustainability of the environment with emphasis on waste management in West Africa, Nigeria.

\section{Design Theories, Aesthetics and Environmental Sustainability}

The sustainability of the environmental has been one of the most passionately examined aspects of sustainability by scholars especially in the field of art, design and technology, with different approaches adopted. One of the major approaches is: "the whole is the sum of the parts" [20]. This design approach, conforming to the system theory, forms the theoretical basis for series of studies conducted by the researcher, a part of which is presented in this paper. The environment is made up of different parts and bits which add up to form the whole. These environmental parts and bits are either natural or built. The simultaneous sustainability of both (the built and the natural environment) is what makes the whole-environment sustainable. When one blossoms at the expense of the other, there are usually consequences. Therefore, both parts of the environment need to develop simultaneously for the balance of sustainability to be maintained. Aesthetics may be used to bridge the gap between both types of environments.

One of the factors that have been linked to environmental sustainability is aesthetics [15]. A previous research [15] established the significance of aesthetics, attainable through proper application of design theories and principles, in achieving a more sustainable environment hinging this aesthetics-sustainability link on the assertion that users of the environment tamper less destructively with structures and installations possessing greater aesthetics. This assertion, this study opines, will translate well into the natural environment as well if properly considered and applied.

Although, the art or design-centred approach has been queried by some researchers [21], it however still portends great value to environmental sustainability. As stated earlier, aesthetics in the built environment may be created with the proper application of selected design theories and principles during design creation and environmental or engineering installation of elements that constitute the built environment [10]. The same may be applied to the shaping or reshaping of the natural environment during human interferences, beautification or conservation attempts. This proper application of design theories yields greater aesthetic positivity in the environment. According to previous studies [10], improved aesthetics foster less destructive interferences from humans. Examples of 'destructive interferences' as used in this study will include unwholesome environmental behaviours such as indiscriminate dumping of solid wastes either in pieces or in large quantities (figures 1, 3, 4, 5 and 6).

\section{The Application of Design/Aesthetic Theories and Principles for Environmental Sustainability}

Research concerning aesthetic response to the environment, whether built or natural, may have a central role in advancing the understanding of human interactions with the environment [12]. This may prove essential in the development and advancement of comprehensive environment related theories [12]. Over the years, different theories and principles have been postulated. Although, few of them might have proven 
slightly fallible, yet many of them have contributed immensely to the development of both the built and the natural environment. Two of such theories, especially as relating to the environment, are:

(i) The Affordance Theory (AT)

(ii) The Environmental Aesthetics and Sustainability Theory (EAST).

\subsection{The Affordance theory (AT)}

The Affordance theory was initiated by James Jerome Gibson. The affordance theory, in relation to the environment, summarily states that the environment is perceived in terms of shapes, spatial relationships and environmental possibilities for action. According to this theory, perception of the environment inevitably leads to some course of action herewith referred to as 'Affordances'. Affordances are evidences in the environment that show possibilities of actions that may be taken [23] while interacting with the environment. Environmental affordances are what the environment offers the users [23, 24]. It is what it affords the user to do with the environment. It offers clues on how an environment may be interacted with or used, good or ill, positively or negatively. As used in this study:

P.E.A.: are clues in the environment that inspire positive responses or environment-friendly behaviour from the user.

N.E.A.: are clues in the environment that inspire negative responses or unfriendly environment behaviour from the user.

However, does the aesthetics of an environment really produce corresponding environmental affordances? Do the environmental affordances of an environment produce corresponding positive or negative user-environment interactions?

\subsection{The Environmental Aesthetics and Sustainability Theory (EAST)}

Based on series of researches conducted, an Environmental Aesthetics and Sustainability Theory was proposed which states that the more aesthetic the environment is, the less destructive interferences it is likely to suffer. This is expected to improve the environment's chances at sustainability and vice versa [10].

A more aesthetic environment possesses less AN. AN has been described as the degree of unattractiveness/ugliness/untidiness resulting from the use, exploitation, shaping, negligence, maintenance (or the lack of maintenance) and 'designing' of the environment. It is the negative perception of beauty that a viewer, user or an observer holds about a design, an installation or a specific environment when viewed as a whole as opposed to aesthetic positivity. AN is the resultant ugliness accruing from environmental misuse, mismanagement and deliberate or unconscious environmental degradation. This AN is as a result of a dearth in the proper application of applicable design theories and principles during i.e. engineering installations [10], environmental creation, shaping, designing, maintenance processes, use or conservation attempts. The AN of any environment consequently increases with less application of appropriate design theories and principles and vice versa [10]. This means that the higher the AN, the lesser the AP of the environment becomes and vice versa. Hence, the aesthetic value of any environment is a function of the AP or AN value of the environment which are in turn dependent on the level of the application of appropriate design theories and principles. In other words, to adjust the aesthetics value of the environment, an environmental designer, engineer or user needs only to adjust the AP or the AN of the environment which in turn influences the level and type of interferences the environment suffers. 
Therefore, this study proposes, in accordance with the EAST, that an environmental system with more AP will consequently suffer less destructive interferences from users because it offers more positive affordances. This means that an environmental system with more AN will suffer more destructive interferences from users usually because it offers less positive affordances which is expected to yield less environmental sustainability. This assertion was tested in the study hypothesis.

\section{Suggested Practical Application of the EAST \& AT Synergy for Environmental Sustainability}

Systems are groups of associated components that interact in a particular environment to perform specific functions that are essential for achieving specified or unspecified objectives. This study considers the environment as a system (in accordance with the system theory). It is composed of various components whose interaction influences the sustainability of the environment. Three of such principal components or players are:

(i) The Environmentalist/ environmental Engineer, Designer or Conserver $\}$ Humans

(ii) The User of the Environment and its components and

(iii) The Environment itself

The Environmentalist/environmental Engineer, Designer or Conserver shapes or conserves the looks or the aesthetics of the environment directly or indirectly creating its affordances. The aesthetics of the environment shapes the perception and attitude of the user towards the environment through its affordances. The user merely responds to the environment either positively or negatively depending on the user perceived affordance of the environment (at any point in time) which in turn is dependent on the AN or AP of the environment. The interaction of these three factors forms a circular cross-influential relationship between humans (the user of the environment) and the environment itself (figure 8).

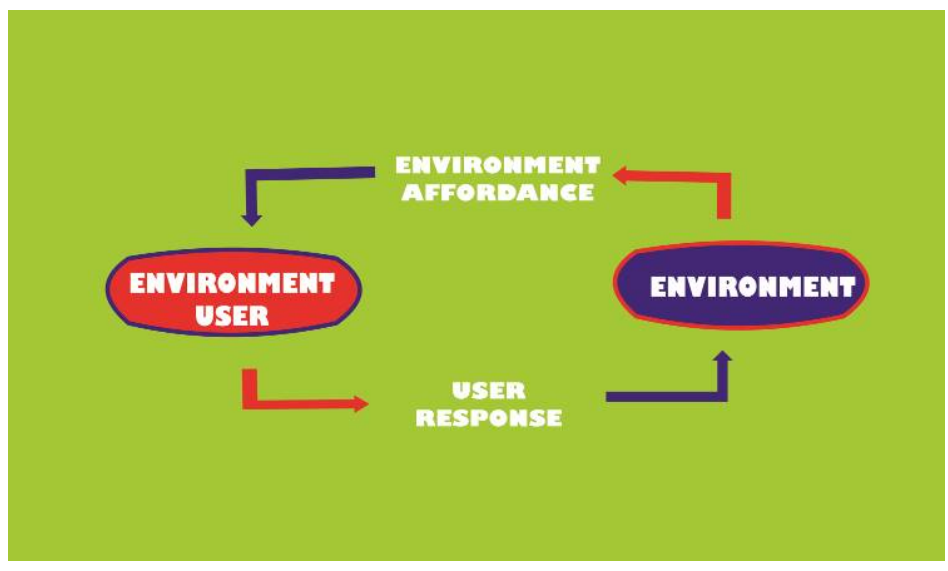

Fig. 8. Showing the interaction of the user and the environment

These factors (the environment, the user and the engineer/designer) are all always active. None is ever passive, except in an environment that has absolutely no environment-human interaction whatsoever, completely isolated and uninhabited. Although, eventually, the designer or conserver of the environment ultimately is also a user just as the user of the environment also contributes to the creation or depletion of the 
aesthetics of the environment through the way he/she uses the environment. The positive interaction of these factors is what sustains the environment at any moment anywhere to achieve balance and sustainability. Where, when and if anyone or all of these three factors falters, the environmental sustainability balance shifts to the negative. For example, if the user responds negatively to the environment i.e. with an environmentally unfriendly behaviour like indiscriminate dumping of solid wastes in inappropriate places, the AN of the environment increases thereby attracting even greater negative responses from the user. That is why the moment people start dumping refuse on a site uninhibited, the dirtier the environment becomes, the more they will dump wastes on the same site and the less it will be easy to make them stop. The principle is very simple. The user merely responds to the EA which in turn is a function of the aesthetics of the environment (figure 8).

In any environmental system, the environmentalist, environmental engineer/designer or conserver may create, manipulate, strive to conserve or work on the environment to make it more aesthetic positive (AP). The environment in turn influences the perception and thereby the attitude of the environment-user favourably towards the environment (in fulfilment of the EAST principle) via positive affordances. The user, in response to the provided EA, acts in more environmentally friendly ways provided the following conditions are met on the part of the user:

(i) The user is in a normal state of mind

(ii) The user is not under any duress or harmful influence and

(iii) The user possesses learned environmentally friendly behaviour or has been, over a period of time, subjected to environmentally friendly education or orientation.

(iv) The user, during perception, must be void of any preconceived or clandestine drives/intentions [25, 26].

As stated earlier, the attitude of humans towards the environment is usually more of a response to the influence the environment itself is having on the human/user than otherwise. Therefore, if the environment 'speaks' or reflects more of AP, then according to the EAST principle, it will experience less destructive human interferences which will in turn optimise sustainability in the environment as a whole. Hence, by making the environment deliberately neat/clean, with much improved AP, the environment, with or without the environmentalist's presence or direct influence, will influence humans to act less negatively towards the environment. This will, for example, reduce the spate of indiscriminate dumping of solid wastes such as shown in figures 1, 3, 4 and 5, hence, protecting the environment. Environmental protection is a vital aspect of environmental sustainability. If only little or nothing is been done to develop the western African environment to the benefits of its inhabitants, at least destructive interferences that impede sustainability may be reduced to the bearable minimum where possible.

\section{Research Method}

This study adopted a fairly triangular method of research. Triangulation of methods is used to check the consistency of the outcomes derived from the adoption of different methods of data collection, capture more details and minimize the effects of bias [27]. Descriptive survey research method was adopted to sample the opinion of the respondents on the aesthetic values of the selected research sites as well as the affordances observable by the respondents on each site. Direct observation was also adopted to validate the opinions of the respondents and check for consistency. Research sites were classified as aesthetically negative sites (e.g. figures 5,9 and 10) which reflect evidences of solid waste indiscriminate dumping. Other research sites were classified as aesthetically positive (e.g. figures 7 and 11) which reflect little or no dumping of solid wastes. Data were collected from different sites concurrently to decipher similar trends and responses to the environment based on the aesthetic values of each selected site. 


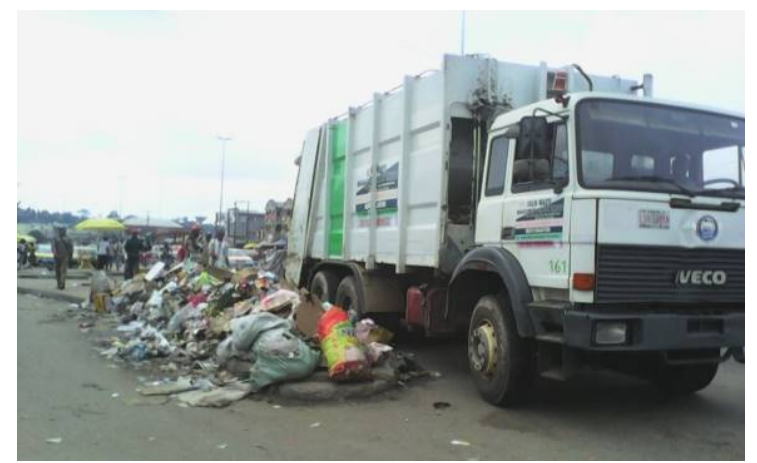

Fig. 9. Aesthetically negative site (featuring prominent solid waste dump)

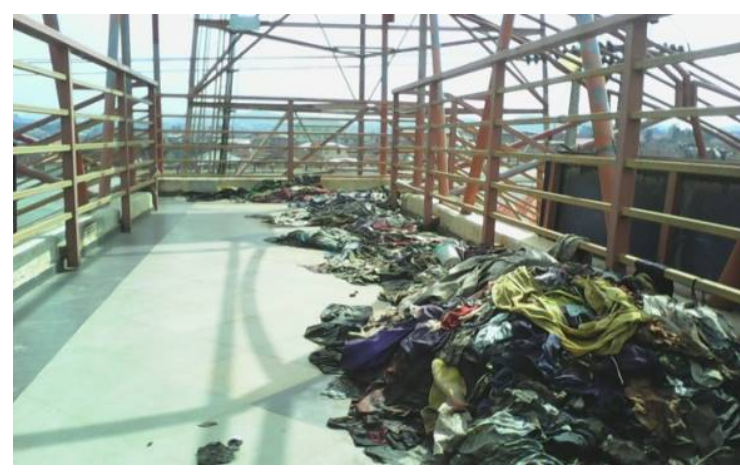

Fig. 10. Aesthetically negative site (featuring prominent solid waste dump)

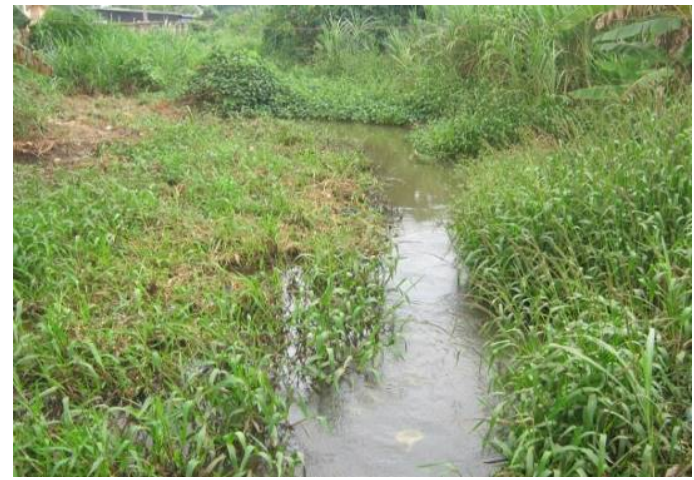

Fig. 11. An aesthetically positive site (featuring little or no solid waste dump)

The sourced data comprised both primary and secondary data. Primary data was acquired via structured questionnaires and direct observation. Secondary data collected included information obtained from the published researches of scholars and journals. The target population for this study included users of the environments in the study area, Nigeria, living or working near the selected research sites. According to a 
previous study [10], many West African environments share many common features. Hence, choosing Nigeria as a study area was considered fairly representative of other West African environments. For the purpose of comparing the data collected, sites selected from western Nigeria was used. Criterion sampling was adopted for the purpose of sampling the respondents. Residing/working near the selected research sites was adopted as criterion. 320 respondents were sampled either individually or in small groups for each environment type with a $94.38 \%$ return rate recorded for the AP environments. A 96.88\% return rate was registered for the AN classified environments. Frequencies and percentages were adopted for analysing the collected data.

\subsection{Research Question}

The following research questions guided this study:

Question 1: Does the AN or AP of an environment produce corresponding EA?

Question 2: Does the EA of an environment produce corresponding negative or positive user-environment interactions?

\subsection{Research Hypothesis}

One hypothesis was tested for the purpose of this study:

- Hypothesis 1:

$\mathrm{H}_{01}$ : Improved environmental aesthetics does not alleviate indiscriminate dumping of solid wastes. Equ. (1) Chi-Square was used to test the research hypothesis.

$$
X^{2}=\sum\left[\frac{\left(f_{e}+f_{o}\right)^{2}}{f_{e}}\right]
$$

In which

$\mathrm{X}^{2}=$ Chi-square

$\mathrm{f}_{\mathrm{o}}=$ Observed frequency

$\mathrm{f}_{\mathrm{e}}=$ Expected frequency

\section{Limitations of the Study}

Difficulty in measuring or defining the exact aesthetic values of environments as it is more of a subjective quantity than otherwise. However, this study is meant to be a guide for further more case specific studies in developing environments.

\section{Results and Analysis}

In order to investigate if the aesthetics value or quality of an environment produces corresponding EA, correspondents' opinions were sampled about the selected AN and AP rated environments which they used. The result is as presented in table 1. Respondents' responses were classified as NEA if the responses represent clues in the environment that inspire negative or unfriendly behaviour or offers little or no restriction to indiscriminate dumping of refuse in the selected environment e.g. "the environment 'suggests' that I can dump my waste here as I drive or walk by". Responses were classified as PEA if they represent clues in the 
environment that inspire positive or friendlier behaviour or offer more restriction (in the mind of the respondents) to indiscriminate dumping of refuse in the selected environment.

Table 1. Users' perception of environmental affordance of selected environments

\begin{tabular}{lllll}
\hline S/N & Environment Type & EA Type & Frequency & Percentage (\%) \\
\hline 1. & AP Environment & PEA & 214 & 71.3 \\
& & NEA & 37 & 12.3 \\
& & Indifferent & 49 & 16.3 \\
& & 300 & $\sim 100$ \\
& Sub-Total & & 45 & 14.5 \\
2. & AN Environment & PEA & 209 & 67.4 \\
& & NEA & 56 & 18.1 \\
& Sub-Total & Indifferent & 310 & 100 \\
& & & \\
& & & \\
& & & \\
\end{tabular}

Table 1 shows that most respondents $(71.3 \%)$ derived a PEA from more AP rated environments than NEA while $16.3 \%$ seemed rather indifferent. This result suggests that a more aesthetically positive environment offers more PEA than NEA. Table 1 also indicates that respondents using AN rated environments derived more NEA (67.4\%) from the AN environments while $18.1 \%$ of the respondents remained neutral/indifferent in their opinions. This result therefore suggests that a more aesthetically negative environment offers more NEA than PEA and vice versa.

The interactions of users with the environment in relation to perceived affordances, positive or negative, were studied. User-Environment interactions in the study areas were rated as positive or negative. All respondents had contact with the environment. Littering of the environment was considered a negative behavior. Not littering, when having the opportunity or reason to litter the environment, was considered a positive behavior. The result is as presented in table 2 .

Table 2. Users' observed interaction with the environment in relation with the perceived EA of the environments

\begin{tabular}{|c|c|c|c|c|}
\hline $\mathbf{S} / \mathbf{N}$ & Environment Type & $\begin{array}{l}\text { User-Environment } \\
\text { Interaction }\end{array}$ & Frequency & Percentage (\%) \\
\hline 1. & $\begin{array}{l}\text { AP Environment } \\
\text { Sub-Total }\end{array}$ & $\begin{array}{l}\text { Positive Behaviour } \\
\text { Negative Behaviour }\end{array}$ & $\begin{array}{l}238 \\
62 \\
300\end{array}$ & $\begin{array}{l}79.3 \\
20.7 \\
100\end{array}$ \\
\hline 2. & $\begin{array}{l}\text { AN Environment } \\
\text { Sub-Total }\end{array}$ & $\begin{array}{l}\text { Positive Behaviour } \\
\text { Negative Behaviour }\end{array}$ & $\begin{array}{l}132 \\
178 \\
310\end{array}$ & $\begin{array}{l}42.6 \\
57.4 \\
100\end{array}$ \\
\hline & Total & & 610 & \\
\hline
\end{tabular}

Table 2 confirms that users $(79.3 \%)$ exhibited more positive environmental behaviours if PEA is perceived from the environment. Conversely, it could be deduced from table 2 that users possess greater tendencies to exhibit more negative behaviour if and when NEA is perceived (57.4\%).

It was, however, observed that not all respondents exhibited positive behaviour because they derived PEA from the environment. Conversely, not all respondents exhibited negative behaviour because of derived NEA. This is evident in the disparity between the number of respondents that perceived PEA in the environment $(71.3 \%$ in table 1$)$ and the number of respondents that exhibited positive behaviour $(79.3 \%$ in table 2$)$. This 
may mean that a percentage of users of the environment exhibit positive behaviours obviously for reasons other than just aesthetics/positive affordances. This is subject to further research.

\subsection{Comparing Data Collected}

The data collected from the study cites in various locations in South western Nigeria (as a case study) is as presented in Tables 3 and 4. Three sites, where equal number of respondents was sampled, were selected from each class of environment (AP or AN rated) for the purpose of comparing the data collected.

Table 3. Users' observed interaction with the environment in relation with the perceived EA on AP rated sites

\begin{tabular}{lllll}
\hline S/N & Sites & User-Environment Interaction & Frequency & Percentage (\%) \\
\hline $\mathbf{1}$ & Site A & Positive Behaviour & 48 & $73.8 \%$ \\
& & Negative Behaviour & 17 & $26.2 \%$ \\
$\mathbf{2}$ & \multirow{2}{*}{ Site B } & Positive Behaviour & 52 & $80 \%$ \\
& & Negative Behaviour & 13 & $20 \%$ \\
$\mathbf{3}$ & \multirow{2}{*}{ Site C } & Positive Behaviour & 49 & $75.4 \%$ \\
& & Negative Behaviour & 16 & $24.6 \%$ \\
\hline
\end{tabular}

As can be deduced from table 3, the positive and negative behaviour are averagely in the ratio 3.3:1 for each AP rated site, confirming that the majority of respondents responded more positively in the AP rated sites.

Table 4. Users' observed interaction with the environment in relation with the perceived EA on AN rated sites

\begin{tabular}{lllll}
\hline S/N & Sites & User-Environment Interaction & Frequency & Percentage (\%) \\
\hline $\mathbf{1}$ & Site A & Positive Behaviour & 32 & $45.1 \%$ \\
& & Negative Behaviour & 39 & $54.9 \%$ \\
$\mathbf{2}$ & Site B & Positive Behaviour & 25 & $35.2 \%$ \\
& & Negative Behaviour & 46 & $64.8 \%$ \\
$\mathbf{3}$ & Site C & Positive Behaviour & 26 & $36.6 \%$ \\
& & Negative Behaviour & 45 & $63.4 \%$ \\
\hline
\end{tabular}

A similar trend is noticeable in the AN rated sites as can be deduced from table 4 . The positive and negative behaviours are averagely in the ratio 1:1.7 for each AN rated site, confirming that majority of respondents responded more negatively in the AN rated sites.

\subsection{Hypothesis testing}

The null hypothesis (H0) asserts the independence of the user's behavioural response (towards the environment i.e. indiscriminate dumping of solid wastes) and the affordance (that stems from the environment's aesthetics). The claims for indifference in the EA perceived from the research sites were ignored for the purpose of testing the hypothesis. Actual behavioural responses were adopted since it has been confirmed (table 1) that more aesthetically positive environments affords the user greater PEA than NEA and vice versa. Chi-square (equ.1) was used to test the research hypothesis. The decision rule was to reject $\mathrm{H} 0$ if the p-value (significance level) is less than alpha (the predetermined significance level, where $\alpha=0.01$ ). 
- Hypothesis 1:

$\mathrm{H}_{\mathrm{O} 1}$ : Improved environmental aesthetics does not alleviate indiscriminate dumping of solid wastes. $\mathrm{H}_{\mathrm{Al}}$ : Improved environmental aesthetics alleviates indiscriminate dumping of solid wastes.

Table 5. Contingency table for hypothesis 1

\begin{tabular}{|c|c|c|c|c|}
\hline Variables & & Positive Behaviour & Negative Behaviour & Marginal row total \\
\hline PEA & & 238 & 62 & 300 \\
\hline NEA & & 132 & 178 & 310 \\
\hline Marginal column total & & 370 & 240 & Grand total $=610$ \\
\hline $\mathbf{N}$ & DF & Chi Square & Significant & Decision \\
\hline 610 & 1 & 86.2935 & $<0.00001$ & Reject $\mathrm{H}_{0}$ \\
\hline
\end{tabular}

The association between perceived EA (accruing from the aesthetic quality) of the environment and the user's behavioural response to the environment, which is supposed to improve or impede the sustainability of the environment, was tested (table 5). A Chi-square of 86.2935 was obtained. P-value less than 0.00001 was derived from the Chi-square score which is far less than the predetermined significance level $(\alpha=0.01)$. Therefore, the result is significant at $\mathrm{p}<0.01$. The null hypothesis is hence rejected while the alternate hypothesis, which establishes a significant association between improved environmental aesthetics and the alleviation of negative user responses to the environment (such as indiscriminate dumping of solid wastes), is thereby accepted.

\section{Conclusion}

The increasing urbanization of many African cities has led to increased generation of solid wastes which are often ill-managed and indiscriminately dumped. Each piece of solid waste dumped on a site reduces the AP of an environment by a fraction, hereby affording users greater NEA. An environment starts suffering greater destructive user-environment interaction the moment one user defaces it, hereby increasing its NEA. For instance, all it takes for an environment to start suffering greater indiscriminate dumping of solid wastes is for one person to dump some wastes there uninhibited, either deliberately or unconsciously, thereby creating or increasing NEA. It then becomes 'normal' or 'more convenient' for other users to dump wastes in the same environment due to increased NEA. Soon, it becomes a 'habit' for many of the users to dump wastes in that same environment as the NEA further increases while PEA decreases simultaneously. Based on this study results, in furtherance of the Environmental-Aesthetics-Sustainability Theory, although subject to further research, this study proposes an improved Environmental Aesthetics-Affordance Theory (EAAT):

\section{The greater the aesthetic positivity of an environment, the lesser the negative environmental affordance it offers, hence, the greater its sustainability.}

This theory is of course premised on the assumption that NEA decreases simultaneously as PEA increases and vice versa. This cuts across both the built and the natural environment. It is therefore safe to conclude that improved environmental aesthetics does alleviate indiscriminate dumping of solid wastes. Cleaner environments have better chances of remaining clean due to greater PEA. Dirtier environments will only get dirtier due to the greater NEA they offer the users. The sustainability of the environment, therefore, depends on the dominant affordance it offers humans. Greater NEA offers less sustainability while greater PEA, as a result of improved AP, offers more sustainability. 


\section{Recommendation}

Based on the results presented already, this study puts forward the following recommendations:

- If every user of the environment makes it a duty to work at and maintain a high AP in their immediate environment, then the environment will offer less NEA and therefore, consequently, will suffer less destructive user-environment interactions/interferences, indiscriminate dumping of solid wastes in urban centres being a part of such interferences.

- Environmental Designers should consciously design positive affordances into the environment to tell the user how to interact with specific environments.

- A percentage of the funds expended on environmental law enforcement (with exception to industrial law enforcement) should be channelled instead into consciously creating higher AP in the environment as well as creating awareness in line with item 1 above. When proper awareness meets greater AP (and PEA), environmental sustainability is improved.

- Design theories and principles and the role of aesthetics in environmental sustainability should be inculcated into the academic/training curriculum of professionals and practitioners that constitute the environmental design field including engineers, architects, environmental scientists and conservers, industrial designers, building technologists, landscape designers, artists, surveyors, environmental law enforcers and even estate managers, to name a few.

Persuasive texts (e.g. figure 12) should only be used as a supporting tool to aid environmentally friendly behaviour and not as the main tool for sustainability drives.

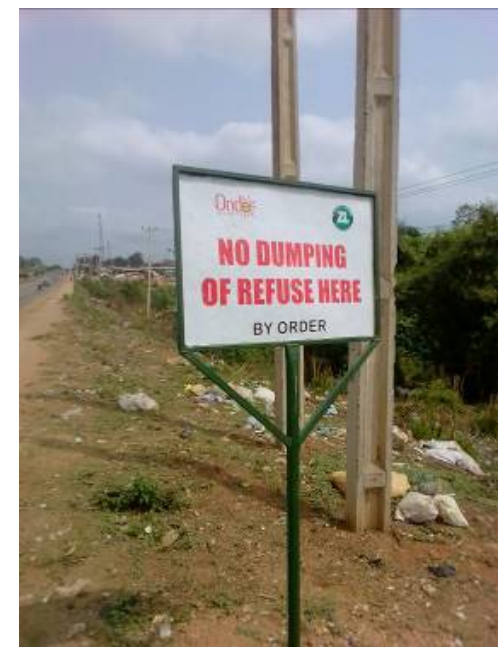

Fig.12. Persuasive texts warning against indiscriminate dumping of refuse

\section{References}

[1] Nordhag, M. "Urbanization in sub-Saharan Africa; A Study of Contemporary Urban Population Growth in a Less Developed Region. c2012. Bachelor thesis, Peace \& Development studies, Linneaus University. [cited 17/3/2018] Available from http://www.diva-portal.org/smash/get/diva2:538141 /FULLTEXT01.pdf

[2] White, J., M.; Mberu, U., B.; Collinson, A., M. “African Urbanization: Recent Trends and Implications.” 
In: Martine, G., ed; McGranahan, G., ed; Montgomery, M., ed; Fernandez-Castilla, R., ed. c2008. The New Global Frontier - Urbanization, Poverty and Environment in the 21st Century. UK/USA: Earthscan. Ch. 18.

[3] Henderson, J.V. "50 years of urbanization in Africa: Examining the role of climate change". c2014 [cited 17/03/2018] https://pdfs.semanticscholar.org/b231/cfe696c42489a3bf0e860b0a39a4af836720.pdf

[4] Keiser J., Utzinger J., Caldas De C. M., Smith T.A., Tanner M., and Singer B.H. "Urbanization in Sub-Saharan Africa And Implication for Malaria Control”. Am. J. Trop. Med. Hyg.,71(Suppl 2), c2004, pp. 118-127. [Copyright (C) 2004 by The American Society of Tropical Medicine and Hygiene]

[5] Mosha, A. C. "Challenges of Urbanization and Development in Africa: The Context of Climate Change". Proceedings of the SB13 Southern Africa Conference, 15-16 October, c2013. Cape Town- South Africa.

[6] Sotunde O. "2014 World Population Day: World Cities Will be Home to Two-thirds of Global Population By 2050.” Bussy Bambo; Africa in Focus. Published online July 10, c2014. [cited 9/1/2019] Available from http://bussybambo.blogspot.com/2014/07/2014-world-population-day-world-cities.html]

[7] Allu, E.L.A. "Built Environment Professionals' Perceptions of Sustainable Urban Built Environment and the Way Forward for Nigeria". International Journal of Arts \& Sciences, c2015, CD-ROM. ISSN: 1944-6934: 08(08):1-8

[8] Golfer, O. "Urbanization Problems In Developing Countries" [Internet]. LinkedIn, Published on July 30, c2015. [cited 9/1/2019] Available from https://www.linkedin.com/pulse/urbanization-problems -developing-countries-golfer-okorie]

[9] Ejaz, N., Akhtar, N., Nisar, H. and Ali Naeem, U. "Environmental impacts of improper solid waste management in developing countries: a case study of Rawalpindi City". WIT Transactions on Ecology and the Environment, Vol 142, c2010 WIT Press. doi:10.2495/SW100351

[10] Odji , E.,"Graphic Design Principles and Theories Application in Rendering Aesthetic and Functional Installations for Improved Environmental Sustainability and Development", International Journal of Engineering and Manufacturing(IJEM), Vol.9, No.1, pp.21-37, 2019.DOI: 10.5815/ijem.2019.01.03

[11] Kaledzi, I., “Africa's pressing need for waste management" [Internet]. Published online 10.07, c2017. [cited 16/01/2019] Available from https://www.dw.com/en/africas-pressing-need-for-wastemanagement/a-39623900

[12] Ulrich R.S., "Aesthetic and Affective Response to Natural Environment". In: Altman I., Wohlwill J.F. (eds) Behavior and the Natural Environment. Human Behavior and Environment (Advances in Theory and Research), c1983, vol 6. Springer, Boston, MA

[13] Shafer, E. L., Jr., \& Mietz, J., "Aesthetic and emotional experiences rate high with northeast wilderness hikers". Environment and Behaviour, c1969, 1, 187-197.

[14] Rossman, B. B., \& Ulehla, Z. J., "Psychological reward values associated with wilderness use: A functional-reinforcement approach",. Environment and Behavior, c1977, 9, 41-66.

[15] Odji, E., "Application of Design Principles and Theories for Achieving Optimized Aesthetics in Designs and Electrical Installations". International Journal of Engineering and Modern Technology, c2018, Vol. 4 No. 3 (International Institute of Academic Research and Development).

[16] Xenakis, I., \& Arnellos, A. "Aesthetics as an Emotional Activity That Facilitates Sense-Making: Towards an Enactive Approach to Aesthetic Experience”. In A. Scarinzi (Ed.), Aesthetics and the Embodied Mind: Beyond Art Theory and the Cartesian Mind-Body Dichotomy, c2015 (pp. 245-259). Springer Netherlands. doi 10.1007/978-94-017-9379-7_15

[17] Mbu, A.D. “The Influence of Environmental Awareness on Human Attitude to Solid Waste Management in Boki Local Government Area of Cross River State”. J Pollut Eff Cont 3:144. c2015. doi: $10.4172 / 2375-4397.1000144$

[18] Ghheadlines, "25 arrested for dumping refuse on highway" [Internet]. Published online Friday 21st July, c2017. [cited 16/01/2019] Available from http://ghheadlines.com/agency/ghana-web/20170721/49599122/25-arrested-for-dumping-refuse-on-highway 
[19] Hadavi S., Kaplan R. and Hunter M, "Environmental affordances: A practical approach for design of nearby outdoor settings in urban residential areas". Landscape and Urban Planning, Volume 134, February c2015, Pages 19-32. https://doi.org/10.1016/j.landurbplan.2014.10.001

[20] Dietrich, K., "Architectural Design Elements" [Internet], RAIC Syllabus, Thesis Submission. SK85ON23, May. c2004 [cited 04 February 2018] Available from: http://www.kdietrich.com/thesis/d9a-research/section\%207\%20design\%20elements/section\%207\%20de sign $\% 20$ elements.pdf

[21] Xenakis I., Arnellos A. “Aesthetic perception and its minimal content: a naturalistic perspective". c2014, Theor. Philos. Psychol. 5:1038. 10.3389/fpsyg.2014.01038

[22] David L, "Affordance Theory (Gibson)," in Learning Theories, July 24, c2014, https://www.learning-theories.com/affordance-theory-gibson.html.

[23] Gibson, J.J., "The Ecological Approach to Visual Perception”. Houghton Mifflin Harcourt (HMH), Boston. c1979.

[24] Norman, D., “The Design of Everyday Things", ISBN 0-465-06710-7, originally published under the title The Psychology of Everyday Things (often abbreviated to POET), c2013.

[25] Kant, I. "Critique of Pure Reason”. c1998. New York: Cambridge University Press

[26] Kant, I., "Critique of the Power of Judgment", 2nd Edn. c2000. New York: Cambridge University Press; $10.1017 / \mathrm{CBO} 9780511804656$

[27] Honorene, J., "Understanding the Role of Triangulation in Research". Scholarly Research Journal for Interdisciplinary Studies SRJIS, , c2017, Vol. Mar-Apr, 2017, 4/31, 91-95.

\section{Author's Profile}

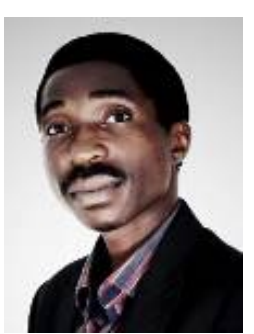

Odji Ebenezer received a B.Tech (with Honours) and a M.Tech in Industrial Design from the Federal University of Technology, Akure. Presently (2019), he is working in the Department of Industrial Design at the Federal University of Technology, Akure, Ondo State, Nigeria. He is pursuing a Ph.D in Industrial Design from the same University. He has published Research papers in National and International peer reviewed Journals and Conferences. His current areas of work include Persuasive Computer Generated Imagery, consumer psychology \& multimedia communication, design theories application \& environmental sustainability and process optimization.

How to cite this paper: Odji Ebenezer, "Aesthetics Application in Solid Waste Management as a Means of Optimising Environmental Sustainability in Urbanizing Third-World Environments", International Journal of Engineering and Manufacturing(IJEM), Vol.9, No.4, pp.15-32, 2019. DOI:10.5815/ijem.2019.04.02 